\title{
Iron loading and large doses of intravenous ascorbic acid promote lipid peroxidation in whole serum in guinea pigs
}

\author{
Maria Kapsokefalou* and Dennis D Miller \\ Cornell Institute of Food Science, Stocking Hall, Cornell University, Ithaca, NY 14853-7201, USA
}

(Received 5 May 1999 - Revised 23 October 1999 - Accepted 5 December 2000)

\begin{abstract}
Large doses of ascorbic acid may mobilise $\mathrm{Fe}$ from $\mathrm{Fe}$-binding proteins in vivo which in turn could catalyse lipid peroxidation, a process associated with degenerative diseases. This hypothesis was tested in vitro in the serum of Fe-loaded animals. Eighteen male guinea pigs weighing about $500 \mathrm{~g}$ on arrival were allocated to two groups of nine. Fe loading was induced in one group by two intraperitoneal injections of $200 \mathrm{mg}$ iron dextran given on days 1 and 5. Blood $(6 \mathrm{ml})$ was drawn from all animals on day 12 by cardiac puncture. Serum and LDL were separated. Serum was tested for loosely-bound Fe (bleomycin assay) and lipid peroxidation (thiobarbituric acid reactive substances (TBARS) assay) and LDL for susceptibility to in vitro oxidation (TBARS and conjugated diene assays). On day 12, another intraperitoneal injection of $200 \mathrm{mg}$ iron dextran was given to the animals in the Fe-loaded group. On day 19, all animals were given $75 \mathrm{mg}$ ascorbic acid by intraperitoneal injection. Blood $(6 \mathrm{ml})$ was drawn $4 \mathrm{~h}$ later by cardiac puncture. Serum and LDL assays were repeated. Ascorbic acid increased looselybound $\mathrm{Fe}$ and in vitro oxidation in the serum from animals of the Fe-loaded group but not in the serum from animals of the control group. Susceptibility of LDL to in vitro oxidation increased after the ascorbic acid injection in the control group but there was no further increase in the Feloaded group. These data suggest that large doses of ascorbic acid promote Fe mobilisation and in vitro oxidation in the serum of Fe-loaded animals.
\end{abstract}

Iron: Ascorbic acid: Oxidation

Peroxidation of lipids in blood and tissues may be involved in degenerative processes associated with chronic diseases such as atherosclerosis (Steinberg et al. 1989). It is therefore pertinent to study lipid peroxidation in vivo, especially factors that may affect the rate of peroxidation. Although the mechanism of lipid peroxidation in vivo is not fully understood, it has been suggested that free Fe may catalyse its initiation (Kanner et al. 1988; Halliwell \& Chirico, 1993). In biological systems, Fe is not free, but bound to biomolecules such as the proteins transferrin, haemoglobin, and ferritin. Mobilisation of Fe from these biomolecules may be required before it can catalyse lipid peroxidation. In vitro experiments suggest that this may occur under certain conditions such as presence of protonating, chelating, or reducing agents including ascorbic acid (Aust, 1987; Gutteridge, 1987). It is uncertain whether Fe mobilisation occurs in vivo, whether ascorbic acid is involved, and whether mobilised Fe is subsequently engaged in pro-oxidant activity. Epidemiological observations, however, associate high-Fe stores with heart disease
(Salonen et al. 1992). Moreover, it has been suggested that large doses of ascorbic acid may be detrimental to haemochromatosis patients (Herbert, 1983). It is therefore important to elucidate the role of ascorbic acid under the conditions of Fe overload in order to better understand the behaviour of ascorbic acid toward oxidation.

The objective of this present study was to test the hypothesis that large doses of ascorbic acid may mobilise Fe from biomolecules in vivo thus promoting in vitro lipid peroxidation in serum, particularly in LDL, in Fe-loaded animals.

\section{Materials and methods \\ Study protocol}

The study protocol was approved by the Institutional Animal Care and Use Committee at Cornell University.

Eighteen male guinea pigs (Hartley strain; Camm Research Institute, Wayne, NJ, USA), weighing about

\footnotetext{
Abbreviations: i.p., intraperitoneal; TBARS, thiobarbituric acid reactive substances.

* Corresponding author: Dr Maria Kapsokefalou, present address Department of Chemistry, University of Crete, Heraklion, POB 1470, Greece, fax +3081210951, email kapsok@athina.cc.uch.gr
} 
Table 1. Dietary information of the commercial guinea-pig diet that was offered to the animals throughout the study*

\begin{tabular}{lr}
\hline Nutrient & Concentration \\
\hline Protein $(\mathrm{g} / \mathrm{kg})$ & 185.00 \\
Fat $(\mathrm{g} / \mathrm{kg})$ & 46.00 \\
Linoleic acid $(\mathrm{g} / \mathrm{kg})$ & 13.00 \\
Fibre $(\mathrm{g} / \mathrm{kg})$ & 146.00 \\
Ash $(\mathrm{g} / \mathrm{kg})$ & 68.00 \\
Iron $(\mathrm{mg} / \mathrm{kg})$ & 235.92 \\
Copper $(\mathrm{mg} / \mathrm{kg})$ & 14.00 \\
Ascorbic acid $(\mathrm{mg} / \mathrm{kg})$ & 1984.00 \\
Vitamin E $(\mathrm{mg} / \mathrm{kg})$ & 77.16 \\
\hline
\end{tabular}

* Prolab, Agway Inc., Syracuse, NY, USA. Ingredients: dehydrated alfalfa meal, wheat middlings, soyabean meal, ground corn, soyabean hulls, ground wheat, animal fat preserved with ethoxyquin, calcium phosphate, sodium chloride, ascorbic acid, magnesium oxide, iron sulfate, iron carbonate, manganous oxide, zinc oxide, copper oxide, calcium iodate, cobalt carbonate, vitamin A acetate, D-activated animal sterol, vitamin E supplement, choline chloride, niacin, riboflavin, menadione sodium bisulfite complex, pyridoxine hydrochloride, thiamine mononitrate, calcium pantothenate, folic acid, biotin, vitamin $B_{12}$ supplement.

$500 \mathrm{~g}$ on arrival, aged 3-5 months, were housed individually in suspended stainless-steel cages with wire-mesh bottoms in a humidity- and temperature-controlled room with a $12 \mathrm{~h}$ light-dark cycle. The animals had free access to distilled water and a commercial guinea-pig diet (Prolab Guinea Pig Formula; Agway Inc., Syracuse, NY, USA) throughout the study (Table 1). The guinea pigs were allocated to two groups of nine animals each so that each group had similar mean body weights. The groups were assigned randomly to either the control or the Fe-loaded group. The procedures of the experiment were as follows (Table 2). On days 1 and 5, each animal from the Fe-loaded group received an intraperitoneal (i.p.) injection of $200 \mathrm{mg}$ $\mathrm{Fe}$ as iron dextran (100 mg Fe/ml; Butler, Colombus, $\mathrm{OH}$, USA). One week later, on day 12, all animals were deprived of food for $8 \mathrm{~h}$ and then given $1 \mathrm{ml}$ saline i.p. injection. They were anaesthetised $4 \mathrm{~h}$ later with an injection of $9 \mathrm{mg}$ Ketamine- $\mathrm{HCl}$ and $0.1 \mathrm{mg}$ Acepromazine (Ft. Dodge Animal Health, Fort Dodge, IA, USA) and kept under anaesthesia with Methoxyflurane (Schering-Plough Animal Health Corp., Union, NJ, USA). Blood (6 ml) was collected from each animal by cardiac puncture. Five ml were delivered into EDTA-containing tubes (2 mg EDTA/ $\mathrm{ml}$ ) on ice, and $1 \mathrm{ml}$ to clean tubes, on ice, for plasma and serum separation, respectively. While still under anaesthesia, animals from the control group received an i.p. injection of $3 \mathrm{mg} \mathrm{Fe}$ as iron dextran to replace $\mathrm{Fe}$ withdrawn in the blood. Animals from the Fe-loaded group received another i.p. injection of $200 \mathrm{mg} \mathrm{Fe}$ as iron dextran. A week later, on day 19, all animals were deprived of food for $8 \mathrm{~h}$ and then injected i.p. with $75 \mathrm{mg}$ ascorbic acid in $1 \mathrm{ml}$ saline. Blood $(6 \mathrm{ml})$ was collected from each animal as on day 12 .

\section{Analytical techniques}

All chemicals were from Sigma Chemical Co. (St Louis, MO, USA) except for thiobarbituric acid, which was from Kodak (Rochester, NY, USA). Iron dextran was from Fisons Corporation (Rochester, NY, USA). Bleomycin (Bleoxane $^{\mathrm{R}}$ ) was a gift of Bristol-Myers Squibb (Princeton, NJ, USA). Analyses in serum were performed on fresh samples. LDL preparation and analyses were completed within $4 \mathrm{~d}$ after blood collection on the same time schedule as for blood collected on days 12 and 19.

Serum was obtained by centrifugation of blood collected into clean tubes at $1000 \mathrm{~g}$ for $15 \mathrm{~min}$ at $4^{\circ} \mathrm{C}$. Plasma was obtained by centrifugation of blood treated with EDTA, as described. LDL $(d=1.019-1.063 \mathrm{~g} / \mathrm{ml})$ was isolated by sequential ultracentrifugation of plasma. Briefly, $3 \mathrm{ml}$ plasma of density adjusted to $1.019 \mathrm{~g} / \mathrm{ml}$ with $84 \mu \mathrm{l}$ $\mathrm{NaBr}, 1.470 \mathrm{~g} / \mathrm{ml}$, was made to $6.05 \mathrm{ml}$ with $\mathrm{NaBr}$, $1.019 \mathrm{~g} / \mathrm{ml}$, and centrifuged at $180000 \mathrm{~g}$ at $4^{\circ} \mathrm{C}$ for $18 \mathrm{~h}$ in a Beckman (Beckman-Coulter Inc, Fullerton, CA, USA) 50.3 rotor. The lower fraction $(4 \mathrm{ml})$ was recovered, brought to $5.50 \mathrm{ml}$ with $\mathrm{NaBr}, 1.019 \mathrm{~g} / \mathrm{ml}$, and adjusted to a density of $1.063 \mathrm{~g} / \mathrm{ml}$ with $0.595 \mathrm{ml} \mathrm{NaBr}, 1.470 \mathrm{~g} / \mathrm{ml}$. After another $14 \mathrm{~h}$ centrifugation at $180000 \mathrm{~g}$ at $4^{\circ} \mathrm{C}$, the top fraction $(2 \mathrm{ml})$, was collected and dialysed in EDTAwashed dialysis tubing (Spectra/Pore, Fisher Scientific, Pittsburgh, PA, USA), molecular mass cut-off 12 000$14000 \mathrm{Da}$ ) against 4 litres of cold PBS, $\mathrm{pH} 7 \cdot 4$, in the dark for $10 \mathrm{~h}$. Dialysis was repeated for a second time with fresh PBS. Protein content of LDL fractions, determined with the

Table 2. Experimental design of the study*

\begin{tabular}{|c|c|c|}
\hline \multirow{2}{*}{$\begin{array}{l}\text { Time-point } \\
\text { (day) }\end{array}$} & \multicolumn{2}{|c|}{ Treatment of groups } \\
\hline & Control & Iron-loaded \\
\hline 0 & \multicolumn{2}{|c|}{ Animals were allocated to groups } \\
\hline 1 & - & $200 \mathrm{mg}$ iron dextran were injected i.p. \\
\hline 5 & - & $200 \mathrm{mg}$ iron dextran were injected i.p. \\
\hline 12 & Food was withdrawn & Food was withdrawn \\
\hline & $\begin{array}{l}\text { After } 8 \mathrm{~h}, 1 \mathrm{ml} \text { saline was injected i.p. } \\
\text { Blood }(6 \mathrm{ml}) \text { was drawn } 4 \mathrm{~h} \text { later } \\
3 \mathrm{mg} \text { iron dextran were injected i.p. }\end{array}$ & $\begin{array}{l}\text { After } 8 \mathrm{~h}, 1 \mathrm{ml} \text { saline was injected i.p. } \\
\text { Blood }(6 \mathrm{ml}) \text { was drawn } 4 \mathrm{~h} \text { later } \\
200 \mathrm{mg} \text { iron dextran were injected i.p. }\end{array}$ \\
\hline 19 & Food was withdrawn & Food was withdrawn \\
\hline & After $8 \mathrm{~h}, 1 \mathrm{ml}$ AA was injected i.p. & After $8 \mathrm{~h}, 1 \mathrm{ml} \mathrm{AA}$ was injected i.p. \\
\hline & Blood (6 ml) blood was drawn $4 \mathrm{~h}$ later & Blood (6 ml) was drawn $4 \mathrm{~h}$ later \\
\hline
\end{tabular}


Peterson-Lowry method (Sigma Kit P-5656), was adjusted to $75 \mu \mathrm{g} / \mathrm{ml}$ with PBS.

Total serum $\mathrm{Fe}$ and transferrin saturation were determined (Sigma kit 565-B). In serum, bleomycin-reactive Fe referred herein as 'loosely-bound Fe' was determined according to Simpson et al. (1992) with the bleomycin assay (Gutteridge \& Hou, 1986; Gutteridge \& Halliwell, 1987). The term 'loosely-bound iron' refers to ionic or weakly chelated $\mathrm{Fe}$ capable of complexing with bleomycin, an antitumour drug. The Fe-bleomycin complex is highly reactive and cleaves DNA releasing thiobarbituric acid reactive substances (TBARS). Briefly, $0.5 \mathrm{ml} 1 \mathrm{mg} / \mathrm{ml}$ DNA (calf thymus, treated with Chelex resin $(0 \cdot 3 \mathrm{~g} / \mathrm{ml}), \mathrm{pH}$ 7, $0.1 \mathrm{ml}$ bleomycin sulfate $(0.5 \mathrm{~g} / \mathrm{l}), 0.1 \mathrm{ml} 50 \mathrm{mM}$ $\mathrm{MgCl}_{2}, \quad 0.1 \mathrm{ml} \quad 0.3 \mathrm{M}-\mathrm{KH}_{2} \mathrm{PO}_{4}-\mathrm{KOH}, \quad \mathrm{pH} \quad 7.4$ (treated with Chelex resin $(0.4 \mathrm{~g} / \mathrm{ml})), 0.1 \mathrm{ml}$ sample, and $0.1 \mathrm{ml}$ $7.5 \mathrm{~mm}$-ascorbic acid (treated with Chelex resin $(0.4 \mathrm{~g} / \mathrm{ml})$ and titrated with dichlorophenolindophenol) were mixed in the order listed and incubated for $1 \mathrm{~h}$ at $37^{\circ} \mathrm{C}$. Standards were prepared from a ferric iron solution (atomic absorption standard) in $0.01 \mathrm{M}-\mathrm{HCl}$ (Chelex treated). The final concentrations were $0.5 \mathrm{mg} \mathrm{DNA} / \mathrm{ml}, 0.05 \mathrm{mg}$ bleomycin/ $\mathrm{ml}, 5 \mathrm{mM}-\mathrm{MgCl}_{2}, 30 \mathrm{mM}$-buffer and $0.75 \mathrm{mM}$-ascorbic acid. To determine TBARS, $0 \cdot 1 \mathrm{ml} 0 \cdot 1 \mathrm{M}$-EDTA, $1 \mathrm{ml}$ thiobarbituric acid $(10 \mathrm{~g} / \mathrm{l})$ and $1 \mathrm{ml} 3 \mathrm{mM}-\mathrm{HCl}$ were added to each sample and control. The mixture was heated for $10 \mathrm{~min}$ at $100^{\circ} \mathrm{C}$ in a boiling-water bath. After the samples cooled, they were centrifuged at $2000 \mathrm{~g}$ for $10 \mathrm{~min}$ and the absorbance of the supernatant fraction was read at $532 \mathrm{~nm}$. The precision of the method may be evaluated from the correlation coefficient of the standard curve $(r$ 0.975) and $\mathrm{CV}$ of duplicate measurements on serum samples $(4.44 \%)$ (Miller \& Miller, 1993).

Lipid peroxidation in serum was determined as TBARS. Serum $(0.1 \mathrm{ml})$ and PBS $(0.4 \mathrm{ml})$, were mixed with $1 \mathrm{ml}$ thiobarbituric acid $(6 \cdot 7 \mathrm{~g} / \mathrm{l})$ and $1 \mathrm{ml}$ TCA $(200 \mathrm{~g} / \mathrm{l})$ and heated at $100^{\circ} \mathrm{C}$ for $30 \mathrm{~min}$. TBARS were extracted with $2 \mathrm{ml}$ butanol and assayed fluorometrically with excitation at $515 \mathrm{~nm}$ and emission at $553 \mathrm{~nm}$. Standards were prepared from tetraethoxypropane, which yields malondialdehyde, in PBS. TBARS were expressed as 'nmol malondialdehyde equivalents'. Susceptibility of LDL to in vitro oxidation was estimated in LDL samples incubated at $37^{\circ} \mathrm{C}$ for $24 \mathrm{~h}$ in the presence of $5 \mu \mathrm{M}-\mathrm{CuSO}_{4}$. Oxidation was expressed as the increase in concentration of TBARS or conjugated dienes in a $24 \mathrm{~h}$ period. Briefly, for the TBARS assay, $0.5 \mathrm{ml}$ LDL containing $37.5 \mu \mathrm{g}$ protein were mixed with $1 \mathrm{ml}$ thiobarbituric acid $(6 \cdot 7 \mathrm{~g} / \mathrm{l})$ and $1 \mathrm{ml}$ TCA $(200 \mathrm{~g} / \mathrm{l})$ and treated as described for the serum samples. The precision of the method may be evaluated from correlation coefficient of the standard curve $(r$ 0.997) (Miller \& Miller, 1993). For the conjugated diene assay, $1 \mathrm{ml}$ LDL containing $75 \mu \mathrm{g}$ protein was mixed with $0.5 \mathrm{mM}^{-\mathrm{CuSO}_{4}}$ to give a final concentration of $5 \mu \mathrm{M}$ $\mathrm{CuSO}_{4}$. Conjugated diene concentration was monitored at $234 \mathrm{~nm}$ (Steinbrecher et al. 1984). The precision of the method may be evaluated from correlation coefficient of the standard curve ( $r$ 0.994) (Miller \& Miller, 1993).

Statistical analysis. Unpaired comparisons between the control and the Fe-loaded group were done with the MannWhitney test (rank sum test for two independent samples).
Table 3. Serum iron and transferrin saturation in the control and in the iron-loaded groups throughout the study $\dagger$

(Mean values and standard deviations for nine animals per group)

\begin{tabular}{|c|c|c|c|c|}
\hline \multirow[b]{2}{*}{ Treatment group } & \multicolumn{2}{|c|}{ Serum iron $(\mu \mathrm{M})$} & \multicolumn{2}{|c|}{ Transferrin saturation } \\
\hline & Mean & SD & Mean & SD \\
\hline \multicolumn{5}{|l|}{ Day 12} \\
\hline Control & 44.7 & $14 \cdot 3$ & 0.48 & 0.17 \\
\hline Iron-loaded & $60 \cdot 5^{\star}$ & $9 \cdot 3$ & $0.78^{*}$ & 0.15 \\
\hline \multicolumn{5}{|l|}{ Day 19} \\
\hline Control & $35 \cdot 1$ & 5.9 & 0.50 & 0.12 \\
\hline Iron-loaded & $63.4^{\star}$ & $16 \cdot 11$ & $0.78^{*}$ & 0.11 \\
\hline
\end{tabular}

Mean values within a column were significantly different from other values (Mann-Whitney test for comparisons between the control and the ironloaded group and Wilcoxon sign-rank test for paired comparisons for data collected before and after the ascorbic acid injections, ${ }^{\star} P<0.05$ ).

† All guinea pigs had free access to distilled water and a commercial guineapig diet throughout the study (see Table 1). Animals from the iron-loaded group were injected intraperitoneally with $200 \mathrm{mg}$ iron dextran on days 1 and 5. All animals were injected intraperitoneally with ascorbic acid on day 19. For details of procedures, see p. 681.

Paired comparisons for data collected before and after the ascorbic acid injections were performed with the Wilcoxon sign-rank test. (Snedecor \& Cochran, 1980). The CI was $95 \%$.

\section{Results}

Serum $\mathrm{Fe}$ concentration and transferrin saturation were determined to assess Fe status (Table 3). Both indices were higher for the Fe-loaded group compared with the control throughout the experiment $(P<0 \cdot 050)$. Treatments on day 12 did not produce any significant change in serum $\mathrm{Fe}$ or transferrin saturation within the control or the Fe-loaded group $(P>0 \cdot 050)$. These results indicate that an Fe-loaded state was induced successfully and that there was no further change to the $\mathrm{Fe}$ status of either group throughout the experimental period.

The body weights of the animals were recorded at various time points throughout the experiment (Table 4).

Table 4. Growth of animals in the control and the iron-loaded group throughout the study $\dagger$

(Mean values and their standard deviations for nine animals per group)

\begin{tabular}{|c|c|c|c|c|}
\hline \multirow{3}{*}{$\begin{array}{l}\text { Time-point of experiment } \\
\text { (day) }\end{array}$} & \multicolumn{4}{|c|}{ Weight of animals $(\mathrm{g})$} \\
\hline & \multicolumn{2}{|c|}{ Control } & \multicolumn{2}{|c|}{ Iron-loaded } \\
\hline & Mean & SD & Mean & SD \\
\hline 0 & $497 \cdot 2$ & 23.4 & $497 \cdot 7$ & $26 \cdot 1$ \\
\hline 7 & $535 \cdot 2$ & $30 \cdot 8$ & 531.9 & $23 \cdot 0$ \\
\hline 11 & $569 \cdot 3^{*}$ & 42.5 & 522.7 & 27.9 \\
\hline 19 & $581.9^{*}$ & $46 \cdot 5$ & $517 \cdot 3$ & $24 \cdot 7$ \\
\hline
\end{tabular}

Mean values in the control group, were significantly different from values in the iron-loaded group on a given day (unpaired comparisons, Mann-Whitney test) and from values in the same group on day 0 (paired comparison within the same group, Wilcoxon sign-rank test) $\left({ }^{\star} P<0.05\right)$.

† All guinea pigs had free access to distilled water and a commercial guineapig diet throughout the study (see Table 1). Animals from the iron-loaded group were injected intraperitoneally with $200 \mathrm{mg}$ iron dextran on days 1 and 5 . All animals were injected intraperitoneally with ascorbic acid on day 19. Blood $(6 \mathrm{ml})$ was drawn for analysis on days 12 and 19. For details of procedures, see p. 681. 
(a)

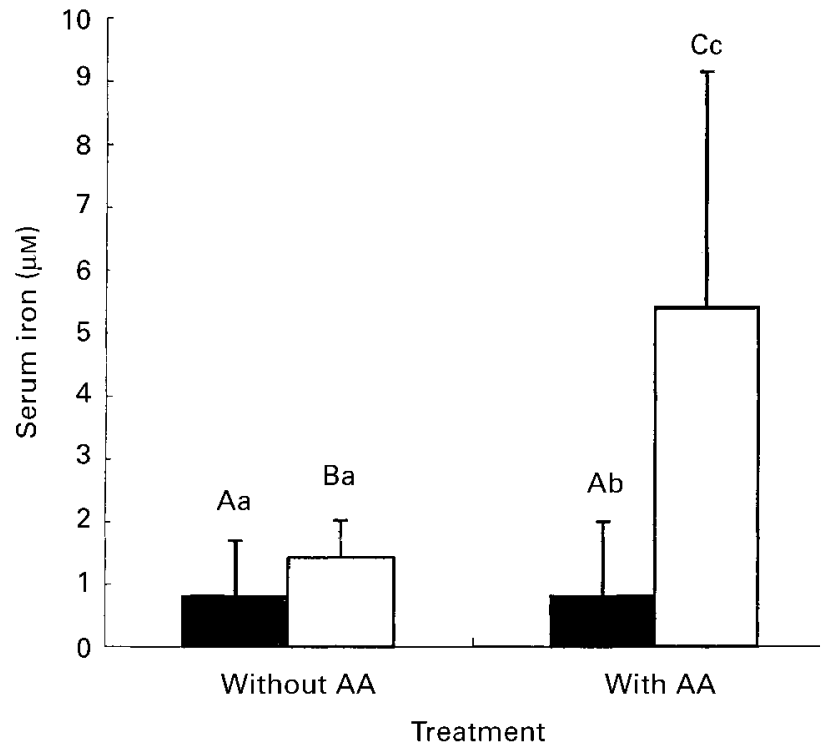

(b)

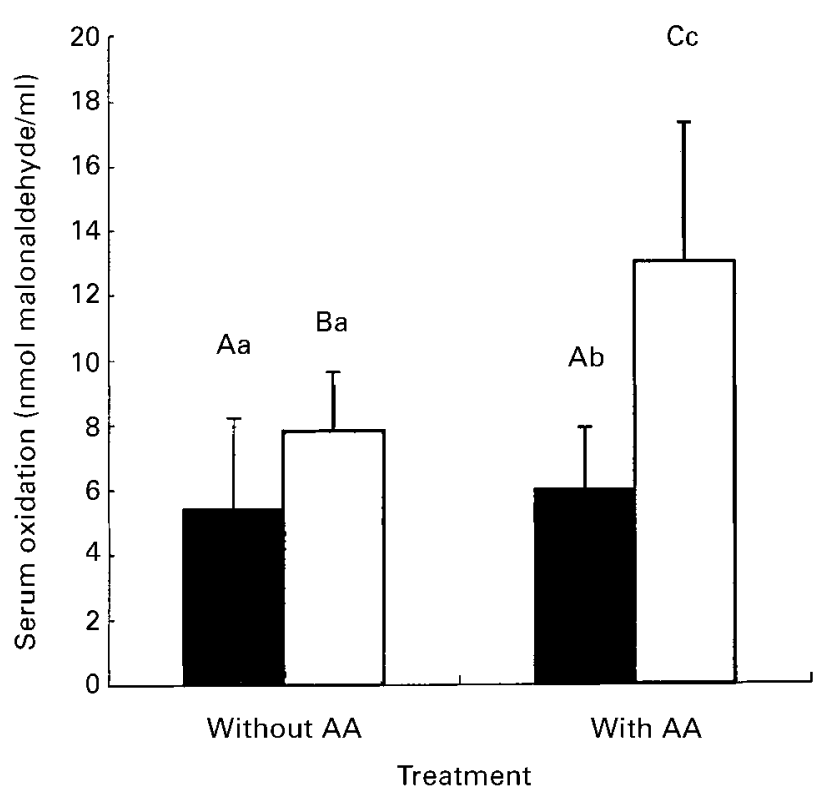

(c)

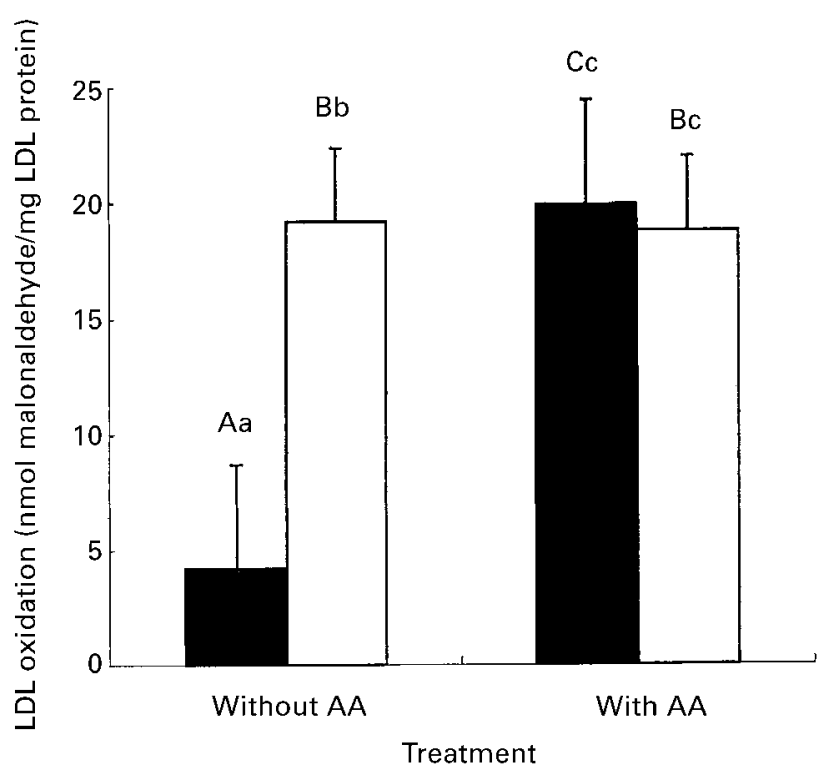

(d)

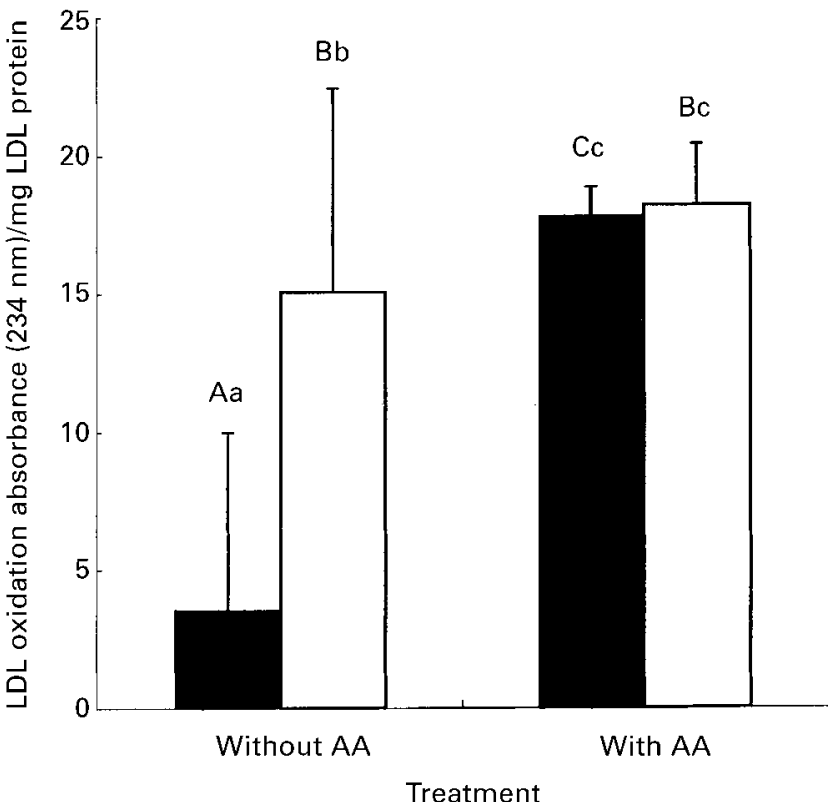

Fig. 1. Effect of an ascorbic acid injection in the control and iron-loaded guinea pigs on (a) loosely bound-iron in serum, (b) lipid peroxidation in serum, (c) susceptibility of LDL to in vitro oxidation assessed as thiobarbituric acid reactive substances (TBARS) and (d) as change in conjugated diene concentration. $\mathbf{\square}$, control; $\square$, iron-loaded. For details of diets and procedures, see Table 1 and p. 681 respectively. In serum, loosely bound iron was measured with the bleomycin method and lipid peroxidation was measured as TBARS. Susceptibility of LDL to in vitro oxidation was assessed in samples incubated at $37^{\circ} \mathrm{C}$ for $24 \mathrm{~h}$ in the presence of $5 \mathrm{mM}-\mathrm{CuSO}_{4}$ and measured as TBARS and as change in conjugated diene concentration. Values are means with standard deviations represented by vertical bars. A, B, C, a, b, c Mean values with unlike superscript letters were significantly different $(P<0.05)$. (A, B, C Comparisons before and after the ascorbic acid injections (in control or iron-loaded animals, Wilcoxon sign-rank test); a, b, c Comparisons between control and iron-loaded animals (with or without ascorbic acid, Mann-Whitney test).)

Initially, and on day 7, there was no difference between the two groups $(P=0.859$ and $P=0.499$ respectively). On days 11 and 19, weights of the animals in the Fe-loaded group were lower than weight of the animals in the control group $(P=0.018$ and $P=0.028$ respectively). Overall (comparison between day 0 and day 19), the animals in the
Fe-loaded group did not grow $(P=0.398)$ while the animals in the control did $(P=0 \cdot 012)$. Some individuals seemed to be affected more than others and were examined by a veterinary surgeon. No signs of disease were identified in the examination. However, it appears that stunted growth in the Fe-loaded group is associated with Fe overloading. 
Loosely-bound Fe (Fig. 1(a)) was not different between the two groups on day $12(P=0 \cdot 186)$ but increased in the Fe-loaded group after the ascorbic acid injection compared with this group on day $12(P=0.017)$ or with the control group after the ascorbic acid injection $(P=0 \cdot 001)$. No change was observed in the control group following ascorbic acid injection $(P=0.498)$. Lipid peroxidation in serum assessed in vitro as TBARS followed the same pattern (Fig. 1(b)), although statistical significance does not allow for equally confident conclusions since $P$ values were barely significant. In particular, TBARS appear no different in the two groups on day $12(P=0.054)$ but higher in the Fe-loaded group after the ascorbic acid injection, compared with the TBARS in the Fe-loaded group on day $12(P=$ 0.042 ) or to the TBARS in the control group after the injection $(P=0.023)$. No change was observed in the control group following ascorbic acid injection $(P=0 \cdot 465)$.

Susceptibility to in vitro oxidation of LDL from the control group was lower than that of LDL from the Feloaded group before the ascorbic acid injection. There was no difference in the susceptibility of LDL to in vitro oxidation between the two groups after the ascorbic acid injection. In particular, incubation of LDL at $37^{\circ} \mathrm{C}$ for $24 \mathrm{~h}$ in the presence of $\mathrm{CuSO}_{4}$ produced higher levels of TBARS in the Fe-loaded group compared with the control group $(P=0.005)$, but only before the ascorbic acid injection. After the injection of ascorbic acid, levels of TBARS increased significantly in the control group $(P=0 \cdot 027)$, but not in the loaded group $(P=0.499)$. There was no difference in TBARS between the control and the Feloaded group after the injections of ascorbic acid $(P=$ 0.560) (Fig. 1(c)). Changes in conjugated diene concentration following LDL oxidation in vitro were very similar to those observed with the TBARS test (Fig. 1(d)). In particular, differences between the control and the Feloaded group in susceptibility of LDL to in vitro oxidation were observed before the ascorbic acid injection $(P=$ $0.004)$ but not after $(P=0.791)$. Susceptibility of LDL to in vitro oxidation increased marginally after the injection of ascorbic acid in the control group $(P=0 \cdot 046)$ but not in the Fe-loaded group $(P=0 \cdot 260)$.

\section{Discussion}

Ascorbic acid, as well as other free radical scavengers, may inhibit lipid peroxidation in vivo. In fact, numerous studies suggest that ascorbic acid contributes to antioxidant defences in a plethora of systems in vitro (Frei et al. 1989; Dasgupta \& Zdunek, 1992) as well as in vivo in animals (Kunert \& Tappel, 1983; Dillard et al. 1984) and in human subjects (Rifici \& Khachadurian, 1993). However, the behaviour of ascorbic acid in in vitro systems that contain high amounts of Fe may be complicated. Ascorbic acid may reduce $\mathrm{Fe}$ to the more reactive ferrous form. Moreover, it has been suggested that both ferrous and ferric Fe must be available to initiate lipid peroxidation (Minotti \& Aust, 1992). Therefore, depending on the experimental conditions, ascorbic acid may act as a pro-oxidant in vitro and in vivo when $\mathrm{Fe}$ is present (O'Connel et al. 1985; Yamamoto \& Niki, 1988; Minotti \& Aust, 1992; Casalino et al. 1996). Observations on the pro-oxidant role of ascorbate in guinea pigs supplemented with high levels of ascorbic acid (Chen \& Chang, 1978) have been reported, however, the mechanism by which ascorbic acid exerts its effect in these systems is not known. It has been suggested (Gutteridge et al. 1983) that, in in vitro model systems, ascorbic acid may reductively release Fe from biomolecules such as ferritin. This Fe may in turn catalyse lipid peroxidation.

In the present study we report a similar observation in the guinea pig. Our data suggest that ascorbic acid promotes the release of $\mathrm{Fe}$ from biomolecules where it is bound. Presumably, some of the released Fe takes the form of ionic $\mathrm{Fe}$ or weakly-chelated $\mathrm{Fe}$ compounds. This Fe, detectable with the bleomycin assay and referred herein as looselybound $\mathrm{Fe}$, has been associated with oxidative processes. Thus, loosely-bound Fe appears to be Fe that is available to catalyse in vivo oxidation (Gutteridge \& Halliwell, 1987). Ferritin is the likely source of this Fe (Gutteridge et al. 1983).

Lipid peroxidation measurements performed in vitro in serum suggest that, in the Fe-loaded group, Fe released by ascorbate promotes oxidative processes. Measurements on the susceptibility of LDL to in vitro oxidation, however, are not in full agreement with these results. In particular, oxidation of LDL from Fe-loaded animals was markedly higher than the control in the absence of injected ascorbic acid. When ascorbic acid was injected, oxidation increased in the control but not in the Fe-loaded group (Fig. 1(C) and (D)). This apparent discrepancy may be due to the fact that LDL oxidation had reached a maximum in the preparation from the Fe-loaded animals without the ascorbic acid injections and therefore did not respond to ascorbic acid injection. LDL from the control animals, on the other hand, was quite resistant to oxidation, leaving room for a response when ascorbic acid was injected. This discrepancy in results between serum and LDL may be at least partially explained by differences in the composition of serum and in vitro preparations of LDL. Serum was used untreated and is expected to contain various antioxidant compounds while the in vitro preparation of LDL was obtained through a procedure that involves removal of plasma fractions including, perhaps, antioxidants. It is therefore expected that serum and LDL may respond differently in in vitro tests. Differences in the methodology employed for testing in vitro oxidation are also important in interpreting these data. While oxidation in serum is assessed under mild in vitro conditions, susceptibility of LDL to in vitro oxidation is assessed under harsh conditions of prolonged heating in the presence of a catalyst. It is not surprising that under the challenge of these conditions, the behaviour of the samples was different (Esterbauer et al. 1992). It follows that if the challenge to oxidation had been done for a shorter time or under less severe conditions, ascorbate addition may have shown an enhancing effect at the Fe-loaded state or at both $\mathrm{Fe}$ levels. Literature suggests, however, that trends in susceptibility to in vitro oxidation are similar for long as well as for short periods of incubation under conditions similar to the conditions employed in this study (Parthasarathy et al. 1990; Reaven et al. 1991). Future time-course studies under various oxidation conditions may provide a further insight into the observed phenomena. 
The effect of time on the treatments applied to the animals was not assessed in the current study. The experimental design employed, allows for paired and unpaired comparisons, however, it does not assess time effects since treatments of the animals and analyses of the samples were performed only on selected time points. Specifically, the effects of $\mathrm{Fe}$ (alone) and of ascorbate were studied only on days 12 and 19 respectively, and were not followed at various time points throughout the experiment. An alternative experimental design that allows tracking of the effects of treatment as well as of time may provide additional insights.

The animals in both groups appeared healthy throughout the experiment and a veterinary surgeon who examined the animals found no signs of disease. Nevertheless, differences in growth rates between the control and the Fe-loaded group suggest that the Fe loading did affect the health of the animals. The size and frequency of the iron dextran dosing were based on a study reported by Dillard et al. (1984). In that study, rats were given 1-2 g iron dextran $/ \mathrm{kg}$ body weight injected i.p. There was no mention of toxic effects in the paper. Therefore, we did not expect a toxic reaction since we injected less iron: $0.8 \mathrm{~g} / \mathrm{kg}$ body weight given as two injected doses of $0.4 \mathrm{~g} / \mathrm{kg}$. Iron dextran is rapidly cleared from the serum (Goldberg \& Martin, 1960), therefore another dose of $0.4 \mathrm{~g} / \mathrm{kg}$ body weight was given to the Fe-loaded group after the first week.

The dose of ascorbic acid as well as the pattern of the injection and blood drawing was based on a study reported by Kunert \& Tappel (1983). The interpretation of the physiological relevance of this dose is related to the requirement for ascorbic acid of the guinea pig. Depending on diet composition, the dietary requirement is $5-50 \mathrm{mg} / \mathrm{kg}$ body weight, i.e. $2 \cdot 5-25 \mathrm{mg}$ for the average $500 \mathrm{~g}$ animal (Poole, 1987). Thus, the injected $75 \mathrm{mg}$ dose was 3-30 times the requirement.

Our data suggest that ascorbic acid mobilises Fe in vivo and the mobilised $\mathrm{Fe}$ catalyses lipid peroxidation assessed in vitro. Although the in vitro tests may reflect in vivo reactions, we cannot conclusively infer that high doses of ascorbic acid lead to in vivo lipid oxidation. However, the present study provides additional support for the hypothesis that high intakes of $\mathrm{Fe}$ and/or ascorbic acid could increase in vivo lipid peroxidation of LDL and therefore could increase risk for atherosclerosis. (Sullivan, 1989). Serum ferritin concentration (Salonen et al. 1992), serum $\mathrm{Fe}$ concentration (Corti et al.1997), and the serum transferrin receptor ratio: serum ferritin ratio (Tuomainen et al. 1998), as well as dietary Fe intakes (Tzonou et al. 1998), are associated with increased risk of myocardial infarction. However, in other studies this positive association between Fe status and atherosclerosis has not been demonstrated (Ascherio et al. 1994; Reunanen et al. 1995). In the First National Health and Nutrition Examination Survey (NHANES I), serum $\mathrm{Fe}$ and transferrin saturation were inversely associated with CHD (Liao et al. 1994).

In summary, the present study showed that in Fe-loaded guinea pigs, ascorbic acid promotes the release of $\mathrm{Fe}$ from biomolecules. Presumably, this loosely-bound $\mathrm{Fe}$ was responsible for the observed increase in peroxidation in the serum of Fe-loaded animals injected with ascorbic acid.
The effect on oxidation of isolated LDL particles was different. Ascorbic acid injection increased LDL oxidation in the control but not in the Fe-loaded animals. Perhaps $\mathrm{Fe}$ loading caused maximal oxidation of isolated LDL so that the increase in loosely-bound Fe caused by ascorbic acid injection had no further effect. These data support the hypothesis that large doses of ascorbic acid mobilise $\mathrm{Fe}$ in vivo in Fe-loaded animals and this $\mathrm{Fe}$ acts as a catalyst for lipid peroxidation in the serum.

\section{References}

Ascherio A, Willet WC, Rimm EB, Giovannucci EL \& Stampfer MJ (1994) Dietary iron intake and risk of coronary disease among men. Circulation 89, 969-974.

Aust SD (1987) Sources of iron for lipid peroxidation in biological systems. In Oxygen radicals and tissue injury, pp. 27-33 [B Halliwell, editor]. Bethesda, MD: Upjohn Co, by the FASEB.

Casalino E, Sblano C \& Landriscina C (1996) A possible mechanism for initiation of lipid peroxidation by ascorbate in rat liver microsomes. International Journal of Biochemistry and Cell Biology 28, 137-149.

Chen LH \& Chang HM (1978) Effects of high level of vitamin C on tissue oxidant status of guinea pigs. International Journal of Vitamin and Nutritional Research 49, 87-91.

Corti MC, Guralnik JM, Salive ME, Ferrucci L, Pahor M, Wallace RB \& Hennekens CH (1997) Serum iron level, coronary artery disease, and all-cause mortality in older men and women. American Journal of Cardiology 79, 120-127.

Dasgupta A \& Zdunek T (1992) In vitro lipid peroxidation of human serum catalyzed by cupric ion: Antioxidant rather than prooxidant role of ascorbate. Life Sciences 50, 875-882.

Dillard JC, Downey JE \& Tappel AL (1984) Effect of antioxidants on lipid peroxidation in iron-loaded guinea pigs. Lipids 19, 127-133.

Esterbauer H, Gebiki J, Puhl H \& Jurgens G (1992) The role of lipid peroxidation and antioxidants in oxidative modification of LDL. Free Radicals in Biology and Medicine 13, 341-390.

Frei B, England L \& Ames BN (1989) Ascorbate is an outstanding antioxidant in human blood plasma. Proceedings of the National Academy of Sciences 86, 6377-6381.

Goldberg L \& Martin LE (1960) Iron overloading phenomena in animals. Toxicology and Applied Pharmacology 2, 683-707.

Gutteridge JM, Halliwell B, Treffry A, Harrision PM \& Blake D (1983) Effect of ferritin-containing fractions with different iron loading on lipid peroxidation. Biochemical Journal 209, 557560.

Gutteridge JM \& Hou Y (1986) Iron complexes and their reactivity in the bleomycin assay for radical-promoting looselybound iron. Free Radical Research Communications 2, 143151.

Gutteridge JM \& Halliwell B (1987) Radical promoting loosely bound iron in biological fluids and the bleomycin assay. Life Chemistry Reports 4, 113-142.

Gutteridge JM (1987) Lipid peroxidation: Some problems and concepts. In Oxygen Radicals and Tissue Injury, pp. 9-19 [B Halliwell, editor]. Bethesda, MD: Upjohn Co, by the FASEB.

Halliwell B \& Chirico S (1993) Lipid peroxidation: its mechanism, measurement, and significance. American Journal of Clinical Nutrition 57, 715S-725S.

Herbert V (1983) Viewpoint. Does mega-C do more good than harm, or more harm than good? Nutrition Today 1, 28-32.

Kanner J, Sofer F, Harell S \& Doll L (1988) Antioxidant activity of ceruloplasmin in muscle membrane and in situ lipid 
peroxidation. Journal of Agricultural and Food Chemistry 36, 415-417.

Kunert KJ \& Tappel AL (1983) The effect of vitamin C on in vivo lipid peroxidation in guinea pigs as measured by pentane and ethane production. Lipids 18, 271-274.

Liao Y, Cooper RS \& McGee DL (1994) Iron status and coronary heart disease: Negative findings from the NHANES I epidemiologic follow-up study. American Journal of Epidemiology 139, 704-712.

Miller JC \& Miller JN (1993) Errors in instrumental analysis; regression and correlation. In Statistics for Analytical Chemistry, 3rd ed.: Ellis Horwood Limited: Chichester, UK.

Minotti G \& Aust S (1992) Redox cycling of iron and lipid peroxidation. Lipids 27, 219-226.

O'Connel MJ, Ward RJ, Baum H \& Peters TJ (1985) The role of iron in ferritin- and haemosiderin-mediated lipid peroxidation in liposomes. Biochemical Journal 229, 135-139.

Parthasarathy S, Khoo JC, Miller E, Barnett J, Witztum JL \& Steinberg D (1990) Low density lipoprotein rich in oleic acid is protected against oxidative modification: Implications for dietary prevention of atherosclerosis. Proceedings of the National Academy of Sciences 87, 3894-3898.

Poole T (1987) The guinea pig. In The UFAW Handbook on the Care and Management of Laboratory Animals, 6th ed.: , pp. 393-410 [T Poole, editor]. London: Longman Scientific \& Technical.

Reaven P, Parthasarathy S, Grasse BJ, Miller E, Almazan F, Mattson FH, Khoo JC, Steinberg D \& Witztum JL (1991) Feasibility of using an oleate-rich diet to reduce the susceptibility of low-density lipoprotein to oxidative modification in humans. American Journal of Clinical Nutrition 54, 701-706.

Reunanen A, Takkunen H, Knekt P, Seppanen R \& Aroma A (1995) Body iron stores, dietary iron intake and coronary heart disease mortality. Journal of Internal Medicine 238, 223-230.

Rifici VA \& Khachadurian AK (1993) Dietary supplementation with vitamins $\mathrm{C}$ and $\mathrm{E}$ inhibits in vitro oxidation of lipoproteins. Journal of the American College of Nutrition 12, 631-637.

Salonen JT, Nyssonen K, Korpela H, Toumilethto J, Sepanen R \& Salonen R (1992) High stored iron levels are associated with excess risk of myocardial infarction in Eastern Finnish men. Circulation 86, 803-811.

Simpson RJ, Cooper CE, Raja KB, Halliwell B, Evans PJ, Aruoma OI, Singh S \& Konijn AM (1992) Non-transferrinbound iron species in the serum of hypotransferrinaemic mice. Biochimica et Biophysica Acta 1156, 19-26.

Snedecor GW \& Cochran WG (1980) Shortcut and nonparametric methods. In Statistical Methods, chapter 8, pp. 135-148. Ames, IA: The Iowa State University Press.

Steinberg D, Parthasarathy S, Carew T, Khoo JC \& Witztum JL (1989) Beyond cholesterol: Modifications of low density lipoprotein that increase its atherogenicity. New England Journal of Medicine 320, 915-924.

Steinbrecher PU, Parthasarathy S, Leake SD, Witztum LJ \& Steinberg D (1984) Modification of low density lipoprotein by endothelial cells involves lipid peroxidation and degradation of low density lipoprotein phospholipids. Proceedings of the National Academy of Sciences 81, 3883-3887.

Sullivan JL (1989) The iron paradigm of ischemic heart disease. American Heart Journal 117, 1177-1188.

Tuomainen TP, Punnonen K, Nyyssonen K \& Salonen JT (1998) Association between body iron stores and the risk of acute myocardial infarction in men. Circulation 97, 1461-1466.

Tzonou A, Lagiou P, Trichopoulou A, Tsoutsos V \& Trichopoulos D (1998) Dietary iron and coronary heart disease risk: a study from Greece. American Journal of Epidemiology 147, 161-166.

Yamamoto K, Niki E, (1988) Interaction of $\alpha$-tocopherol with iron: antioxidant and prooxidant effects of $\alpha$-tocopherol in the oxidation of lipids in aqueous dispersions in the presence or iron. Biochimica et Biophysica Acta 958, 19-23. 